Hox Pmamo ose 1940 ROMANCE

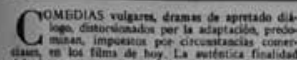
and

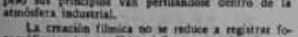

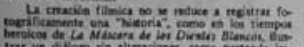

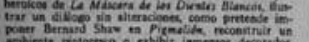

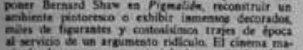

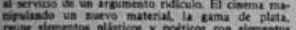

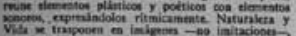
por el antilice de la lotognis

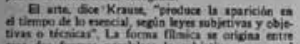

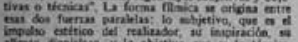

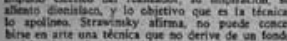

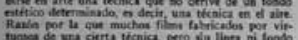

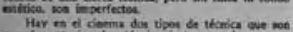

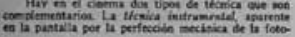

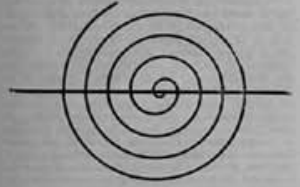

chosecus tafronar

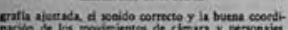

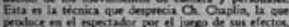

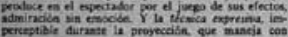<smiles>CC12C3CC1C32</smiles>

and

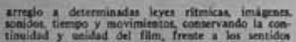

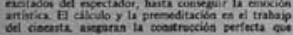

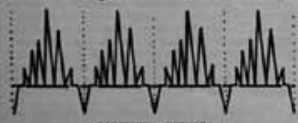

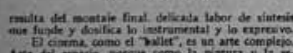

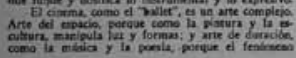

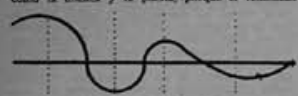

urrho de Cidescins

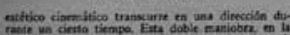

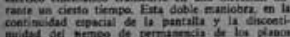

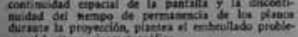

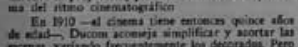

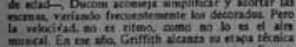

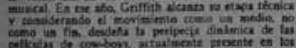

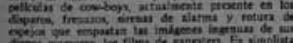

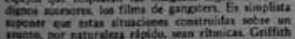

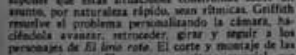

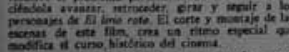

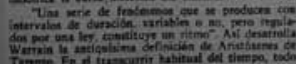

RITMO Y CINEMA

Pon Cintos vza

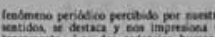

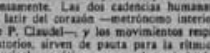

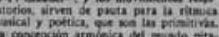

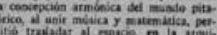

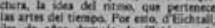

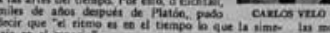

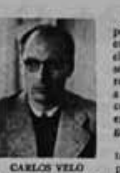

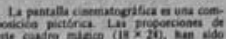

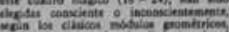

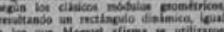

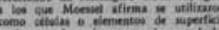

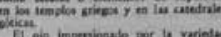

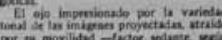

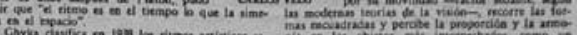

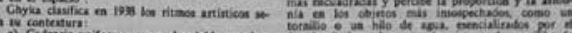

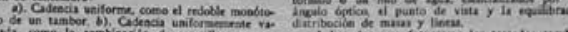

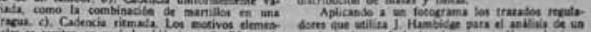

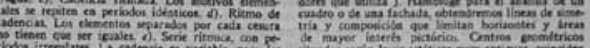

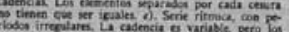

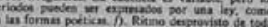

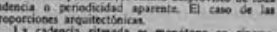

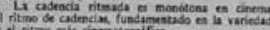

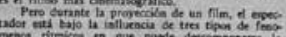

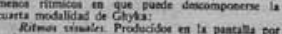

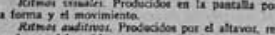
notue de limagn-honido

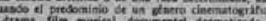

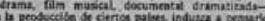

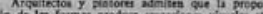

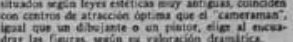

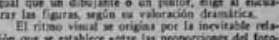

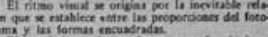

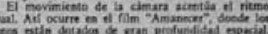

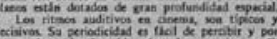

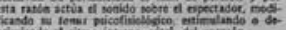

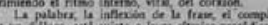

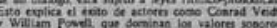

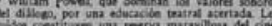

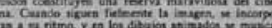

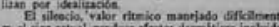

\section{A L A D E R I V A}

RL GENIO Y SUS CONSECUEN.

$\mathrm{H}$

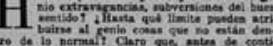

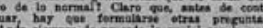

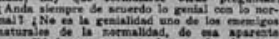

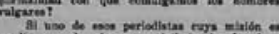

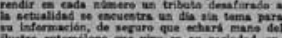

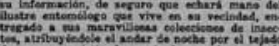

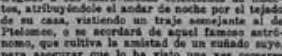

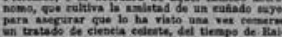

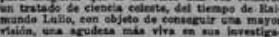

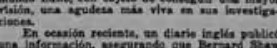

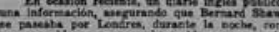

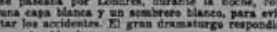

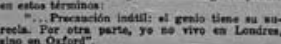

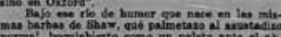

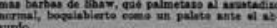

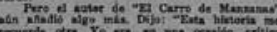

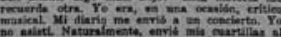

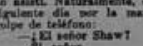

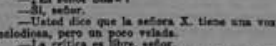

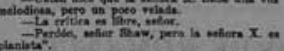
¿CONOCEN USTRDFS A MARGA

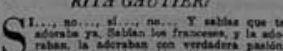

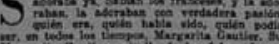

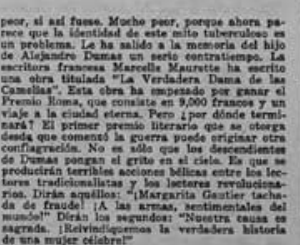

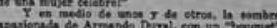

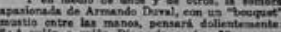
LENGUAS VIVAS Y MUERTAS

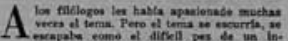

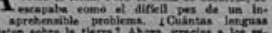

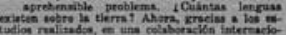

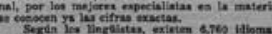

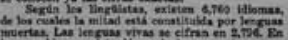

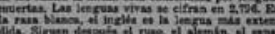

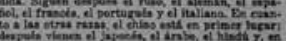

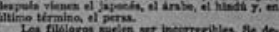

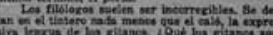

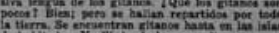

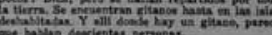
PICASSO MOVIIIZADO

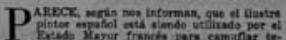

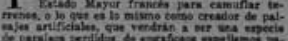

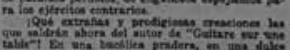

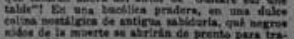

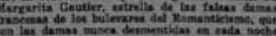

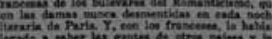

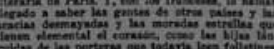

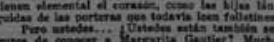

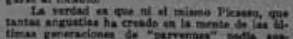

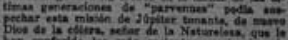

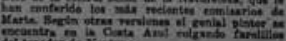

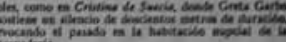

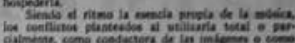

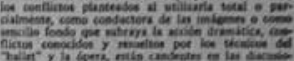

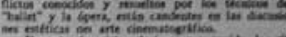

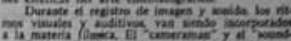

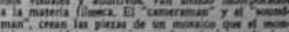

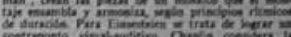

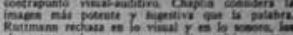

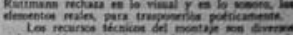

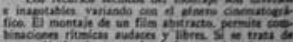

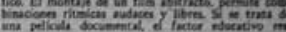

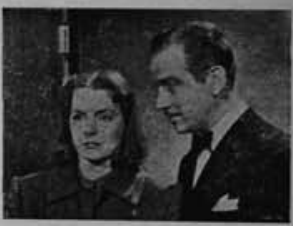

mocaure de car nurx. a.

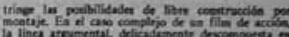

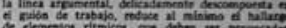

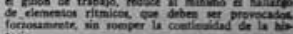

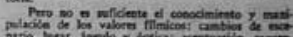

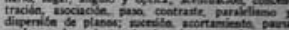

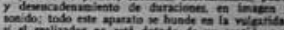

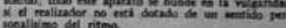

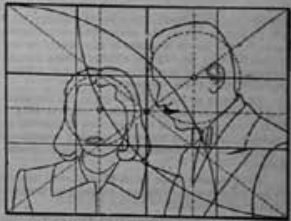

whes emoco ben rotrocaure

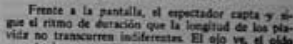

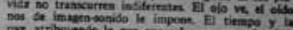

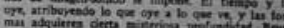

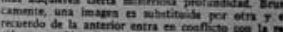

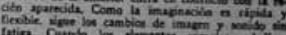

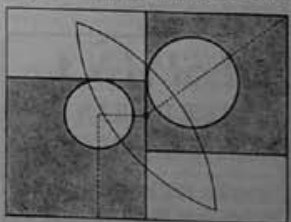

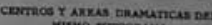

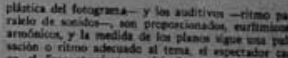

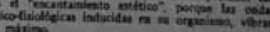

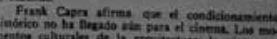

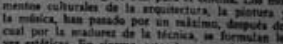

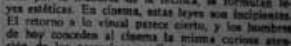

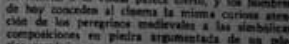

Carlos Velo, "Ritmo y Cinema", Romance. Revista Popular Hispanoamericana, año I, n 2, 15 de febrero de 1940, p. 17 (ed. Facsímil, Verlag Detlev Auvermann KG, Glasshütten im Taunus, 1974) Biblioteca Xeral da Universidade de Santiago de Compostela 


\section{RITMO Y CINEMA}

Por Carlos Velo

Comedias vulgares, dramas de apretado diálogo, distorsionados por la adaptación, predominan, impuestos por circunstancias comerciales en los films de hoy. La auténtica finalidad del cinema, como arte de nuestra época, se desvía, pero sus principios van perfilándose dentro de la atmósfera industrial.

La creación fílmica no se reduce a registrar fotográficamente una "historia", como en los tiempos heroicos de La Máscara de los Dientes Blancos, ilustrar un diálogo sin alteraciones, como pretende imponer Bernard Shaw en Pigmalión, reconstruir un ambiente pintoresco o exhibir inmensos decorados, miles de figurantes y costosísimos trajes de época al servicio de un argumento ridículo. El cinema manipulando un nuevo material, la gama de plata, reúne elementos plásticos y poéticos con elementos sonoros, expresándolos rítmicamente. Naturaleza y Vida se trasponen en imágenes -no imitaciones-, por el artificio de la fotografía.

El arte, dice Krause, "produce la aparición en el tiempo de lo esencial, según leyes subjetivas y objetivas o técnicas". La forma fílmica se origina entre esas dos fuerzas paralelas: lo subjetivo, que es el impulso estético del realizador, su inspiración, su aliento dionisíaco, y lo objetivo que es la técnica, lo apolíneo. Strawinsky afirma, no puede concebirse en arte una técnica que no derive de un fondo estético determinado, es decir, una técnica en el aire. Razón por la que muchos films fabricados por virtuosos de una cierta técnica, pero sin línea ni fondo estético, son imperfectos

Hay en el cinema dos tipos de técnica que son complementarios. La técnica instrumental, aparente en la pantalla por la perfección mecánica de la fotografía ajustada, el sonido correcto y la buena coordinación de los movimientos de cámara y personajes. Esta es la técnica que desprecia Ch. Chaplin, la que produce en el espectador por el juego de sus efectos, admiración sin emoción. Y la técnica expresiva, imperceptible durante la proyección, que maneja con arreglo a determinadas leyes rítmicas, imágenes, sonidos, tiempo y movimientos, conservando la continuidad y unidad del film, frente a los sentidos excitados del espectador, hasta conseguir la emoción artística. El cálculo y la premeditación en el trabajo del cineasta, aseguran la construcción perfecta que resulta del montaje final, delicada labor de síntesis que funde y dosifica lo instrumental y lo expresivo.

El cinema, como el "ballet", es un arte complejo. Arte del espacio, porque como la pintura y la escultura, manipula luz y formas; y arte de duración, como la música y la poesía, porque el fenómeno estético cinemático transcurre en una dirección durante un cierto tiempo. Esta doble maniobra, en la continuidad espacial de la pantalla y la discontinuidad del tiempo de permanencia de los planos durante la proyección, plantea el embrollado problema del ritmo cinematográfico.

En 1910 -el cinema tiene entonces quince años de edad-, Ducom aconseja simplificar y acortar las escenas, variando frecuentemente los decorados. Pero la velocidad no es ritmo, como no lo es el aire musical. En ese año, Griffith alcanza su etapa técnica y considerando el movimiento como un medio, no como un fin, desdeña la peripecia dinámica de las películas de cow-boys, actualmente presente en los disparos, frenazos, sirenas de alarma y rotura de espejos que empastan las imágenes ingenuas de sus dignos sucesores, 
los films de gangsters. Es simplista suponer que estas situaciones construidas sobre un asunto, por naturaleza rápido, sean rítmicas. Griffith resuelve el problema personalizando la cámara, haciéndola avanzar, retroceder, girar y seguir a los personajes de El lirio roto. El corte y montaje de las escenas de este film, crea un ritmo especial que modifica el curso histórico del cinema.

"Una serie de fenómenos que se producen con intervalos de duración, variables o no, pero regulados por una ley, constituye un ritmo". Así desarrolla Warrain la antiquísima definición de Aristóxenes de Tarento. En el transcurrir habitual del tiempo, todo fenómeno periódico percibido por nuestros sentidos, se destaca y nos impresiona intensamente. Las dos cadencias humanas, el latir del corazón -metrónomo interior de P. Claudel-, y los movimientos respiratorios, sirven de pauta para la rítmica musical y poética, que son las primitivas. La concepción armónica del mundo pitagórico, al unir música y matemática, permitió trasladar al espacio, en la arquitectura, la idea del ritmo, que pertenece a las artes del tiempo. Por esto, d'Eichtall, miles de años después de Platón, pudo decir que "el ritmo es en el tiempo lo que la simetría en el espacio".

Ghyka clasifica en 1938 los ritmos artísticos según su contextura:

a) Cadencia uniforme, como el redoble monótono de un tambor. b) Cadencia uniformemente variada, como la combinación de martillos en una fragua. c) Cadencia ritmada. Los motivos elementales se repiten en períodos idénticos. d) Ritmo de cadencias. Los elementos separados por cada cesura no tienen que ser iguales. e) Serie rítmica, con períodos irregulares. La cadencia es variable, pero los períodos pueden ser expresados por una ley, como en las formas poéticas. f) Ritmo desprovisto de toda cadencia o periodicidad aparente. El caso de las proporciones arquitectónicas.

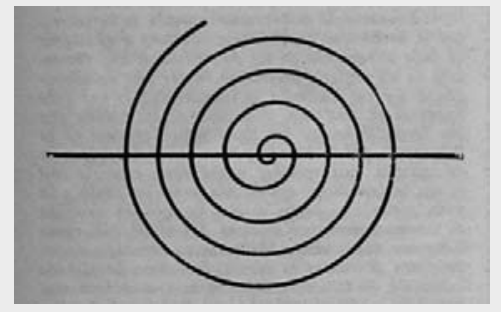

Cadencia uniforme

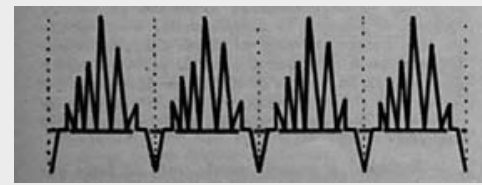

Cadencia rítmica

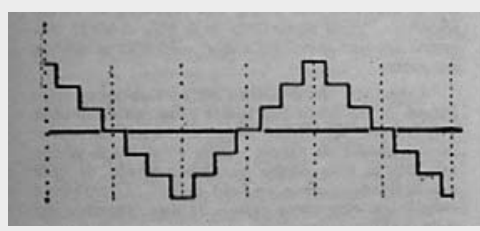

Cadencia uniformemente varoada

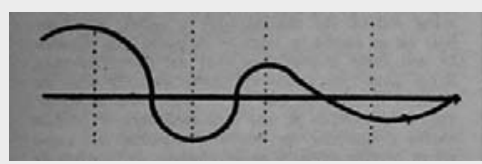

Ritmo de cadencias

La cadencia ritmada es monótona en cinema. El ritmo de cadencias, fundamentado en la variedad, es el ritmo más cinematográfico. 
Pero durante la proyección de un film, el espectador está bajo la influencia de tres tipos de fenómenos rítmicos en que puede descomponerse la cuarta modalidad de Ghyka:

-Ritmos visuales. Producidos en la pantalla por la forma y el movimiento.

-Ritmos auditivos. Producidos por el altavoz, reproductor del sonido.

-Ritmos de tiempo. Producidos por el corte y montaje de imagen-sonido.

No existen concepciones rítmicas específicas de una escuela artística o de una raza determinada, aun cuando el predominio de un género cinematográfico -drama, film musical, documental dramatizada-, en la producción de ciertos países, induzca a pensarlo.

Arquitectos y pintores admiten que la proporción de las formas produce sensaciones visuales rítmicas.

La pantalla cinematográfica es una composición pictórica. Las proporciones de este cuadro mágico $(18 \times 24)$ han sido elegidas consciente o inconscientemente, según los clásicos módulos geométricos, resultando un rectángulo dinámico, igual a los que Moessel afirma se utilizaron como células o elementos de superficie en los templos griegos y en las catedrales góticas.

El ojo impresionado por la variedad tonal de las imágenes proyectadas, atraído por su movilidad -factor sedante, según las modernas teorías de la visión-, recorre las formas encuadradas y percibe la proporción y la armonía en los objetos más insospechados, como un tornillo o un hilo de agua, esencializados por el ángulo óptico, el punto de vista y la equilibrada distribución de masas y líneas.

Aplicando a un fotograma los trazados reguladores que utiliza J. Hambidge para el análisis de un cuadro o de una fachada, obtendremos líneas de simetría y composición que limitan horizontes y áreas de mayor interés pictórico. Centros geométricos situados según leyes estéticas muy antiguas, coinciden con centros de atracción óptima que el "cameraman", igual que un dibujante o un pintor, elige al encuadrar las figuras, según su valoración dramática.

El ritmo visual se origina por la inevitable relación que se establece entre las proporciones del fotograma y las formas encuadradas.

El movimiento de la cámara acentúa el ritmo visual. Así ocurre en el film Amanecer, donde los planos están dotados de gran profundidad espacial.

Los ritmos auditivos en cinema, son típicos y decisivos. Su periodicidad es fácil de percibir y por esta razón actúa el sonido sobre el espectador, modificando su tonus psicofisiológico, estimulando o deprimiendo el ritmo interno, vital, del corazón.

La palabra, la inflexión de la frase, el compás de un diálogo, está sujeto a leyes rítmico-prosódicas. Esto explica el éxito de actores como Conrad Veidt y William Powell, que dominan los valores sonoros del diálogo, por una educación teatral acertada. Los ruidos constituyen una reserva maravillosa del cinema. Cuando siguen fielmente la imagen, se incorporan a su ritmo, y en los dibujos animados se musicalizan por idealización.

El silencio, valor rítmico manejado difícilmente en el cine actual, produce efectos dramáticos inolvidables, como en Cristina de Suecia, donde Greta Garbo sostiene un silencio de doscientos metros de duración, evocando el pasado en la habitación nupcial de la hospedería. 
Siendo el ritmo la esencia propia de la música, los conflictos planteados al utilizarla total o parcialmente, como conductora de las imágenes o como sencillo fondo que subraya la acción dramática, conflictos conocidos y resueltos por los técnicos del "ballet" y la ópera, están candentes en las discusiones estéticas del arte cinematográfico.

Durante el registro de imagen y sonido, los ritmos visuales y auditivos van siendo incorporados a la materia fílmica. El "cameraman" y el "soundman", crean las piezas de un mosaico que el montaje ensambla y armoniza, según principios rítmicos de duración. Para Eisenstein se trata de lograr un contrapunto visual-auditivo. Chaplin considera la imagen más potente y sugestiva que la palabra. Ruttmann rechaza en lo visual y en lo sonoro, los elementos reales, para trasponerlos poéticamente.

Los recursos técnicos del montaje son diversos e inagotables, variando con el género cinematográfico. El montaje de un film abstracto, permite combinaciones rítmicas audaces y libres. Si se trata de una película documental, el factor educativo restringe las posibilidades de libre construcción por montaje. En el caso complejo de un film de acción, la línea argumental, delicadamente descompuesta en el guión de trabajo, reduce al mínimo el hallazgo de elementos rítmicos, que deben ser provocados, forzosamente, sin romper la continuidad de la historia.

Pero no es suficiente el conocimiento y manipulación de los valores fílmicos: cambios de escenario, lugar, ángulo y óptica; acentuación, concentración, asociación, paso, contraste, paralelismo y dispersión de planos; sucesión, acortamiento, pausa y desencadenamiento de duraciones, en imagen y sonido; todo este aparato se hunde en la vulgaridad si el realizador no está dotado de un sentido personalísimo del ritmo.

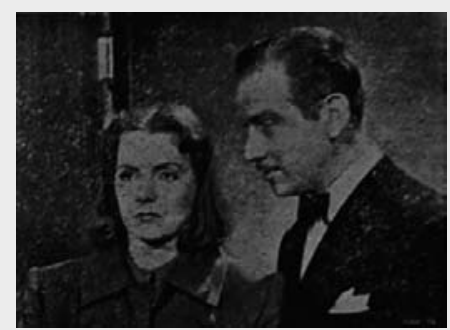

Fotograma de un film M.G.M.

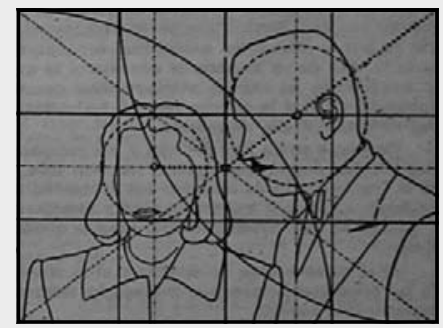

Análisis rítmico del fotograma

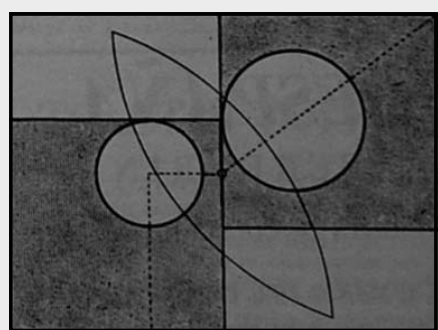

Centros y áreas dramáticas del mismo fotograma 
Frente a la pantalla, el espectador capta y sigue el ritmo de duración que la longitud de los planos de imagen-sonido le impone. El tiempo y la vida no transcurren indiferentes. El ojo ve, el oído oye, atribuyendo lo que oye a lo que ve, y las formas adquieren cierta misteriosa profundidad. Bruscamente, una imagen es substituida por otra y el recuerdo de la anterior entra en conflicto con la recién aparecida. Como la imaginación es rápida y flexible, sigue los cambios de imagen y sonido sin fatiga. Cuando los elementos visuales -belleza plástica del fotograma- y los auditivos -ritmo paralelo de sonidos-, son proporcionados, eurítmicos, armónicos, y la medida de los planos sigue una pulsación o ritmo adecuado al tema, el espectador cae en el "encantamiento estético", porque las ondas psico-fisiológicas inducidas en su organismo, vibran al máximo.

Frank Capra afirma que el condicionamiento histórico no ha llegado aún para el cinema. Los momentos culturales de la arquitectura, la pintura y la música, han pasado por un máximo, después del cual por la madurez de la técnica, se formulan leyes estéticas. En cinema, estas leyes son incipientes. El retorno a lo visual parece cierto, y los hombres de hoy conceden al cinema la misma curiosa atención de los peregrinos medievales a las simbólicas composiciones en piedra argumentada de un pórtico románico. 